\title{
Fidelização de Clientes como Ferramenta Estratégica: Uma Pesquisa de Campo realizada com Clientes de Mercantis localizados na cidade de Brejo Santo-CE
}

\author{
Laleska Zuza Pereira ${ }^{1}$; Márcia Maria Leite ${ }^{2}$
}

\begin{abstract}
Resumo: Diante dos avanços da globalização que se faz presente em todo mundo, as organizações empresariais necessitam buscar novos modos de inovação para permanecerem competitivas. Neste contexto de inovação é mudança o presente artigo tem como objetivo geral identificar quais os principais fatores que influenciam os clientes a optarem por determinado mercantil na cidade de Brejo Santo-CE. Dentre os objetivos específicos, estudar as estratégias de fidelização como diferencial competitivo, fazer uma sondagem da aplicabilidade dos benefícios da fidelização e por fim apresentar os resultados obtidos através da pesquisa. Para o alcance dos resultados, foi realizado uma pesquisa de opinião pública, de natureza bibliográfica de cunho quantitativo, exploratório e descritivo. Como resultados obtidos foi possível identificar as mudanças de comportamento do consumidor, questões relacionadas ao perfil socioeconômico, a falta de gerenciamento de estratégia dos mercantis, a falta de pesquisa de mercado e de um bom atendimento ao cliente.
\end{abstract}

Palavras Chave: Fidelização. Planejamento Estratégico. Mercantis.

\section{Customer Loyalty as a Strategic Tool: A Field Survey conducted with Mercantile Customers located in the city of Brejo Santo, State of Ceará}

\begin{abstract}
Before the progress of the globalization that it is made present in everybody, the business organizations need to look for new innovation manners for us to stay competitive. In this innovation context it is change the present article has at general objective to identify which the main factors that influence the customers to choose her for certain mercantile in the city of Swamp Saint-CE. Among the specific objectives, to study the loyalty strategies at differential competitive, to do the survey of the applicability of the benefits of the loyalty and finally to present the results obtained through the research. For the reach of the results, the research of public opinion was accomplished, of bibliographical nature of stamp quantitative, exploratory and descriptive. At obtained results were possible to identify the changes of the consumer's behavior, subjects related to the socioeconomic profile, the lack of administration of strategy of the mercantile ones, the lack of market research and of the good service to the customer.
\end{abstract}

Keywords: Loyalty. Strategic planning. Mercantis.

\footnotetext{
${ }^{1}$ Graduanda em Administração, Centro Universitário Doutor Leão Sampaio, Juazeiro do Norte, Ceará, laleska_z@hotmail.com

${ }^{2}$ Especialização em Gestão Estratégica de Pessoas, Centro Universitário Doutor Leão Sampaio, Juazeiro do Norte, Ceará, marcialeite@leaosampaio.edu.br
}

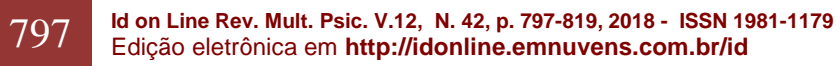




\section{Introdução}

O mundo atual encontra-se em um constante processo de globalização, dessa forma um indivíduo pode vir a ter o que deseja com maior facilidade. Os mercados estão em expansão, existe uma maior circulação de bens e uma busca constante pelo aperfeiçoamento de processos. Dessa forma, afim de sanar os problemas derivados da competitividade as organizações necessitam apostar em diferenciais estratégicos e consequentemente alcançar a fidelização de seus clientes. Como forma de aprofundar o estudo a respeito do impacto da fidelização sobre os consumidores, será realizado um estudo de opinião pública com o foco nos clientes dos mercantis situados na cidade de Brejo Santo-CE.

A cidade de Brejo Santo-CE, foi escolhida em virtude aos dados apresentados pelo Instituto de Pesquisa e Estratégia Econômica do Ceará (IPECE) 2016, segundo o mesmo, o município possui um índice de desenvolvimento de 35,65\% que é considerado alto para uma cidade de seu porte, por esse motivo dispõe de diversos estabelecimentos voltados a prestação de serviço. A partir da temática aqui abordada, torna-se necessário investigar a seguinte questão: As estratégias voltadas para fidelização de clientes são consideradas atrativas para os consumidores que efetuam suas compras em mercados localizados em Brejo Santo-CE?

A resposta para essa pergunta pode variar de individuo para individuo, entretanto, as hipóteses elencadas são: um ótimo atendimento durante a venda e pós-venda; a busca por inovações que as possibilitem as empresas a atrair novos clientes; uso das redes sociais; a fidelização do cliente pode influenciar a competitividade das organizações; diferenciação no preço e no mix de produtos que pode ser um fator de fidelização e pôr fim a rapidez na entrega de produtos que poderá ser um diferencial.

Sabendo que a fidelização de clientes é a maior riqueza de uma empresa, um estudo realizado pelo Serviço Brasileiro de Apoio às Micro e pequenas Empresas - SEBRAE (2017) indica que , conquistar um novo cliente custa para a empresa cinco vezes mais do que manter um cliente excelente, além disso estima-se que cerca de $65 \%$ dos negócios venha de clientes já existentes e não de novos cientes.

No entanto, o objetivo geral deste artigo é identificar quais os principais fatores que influenciam os clientes a optarem por determinado mercantil na cidade de Brejo Santo-CE. Dentre os objetivos específicos estão, estudar as estratégias de fidelização como diferencial 
competitivo, fazer uma sondagem da aplicabilidade dos benefícios da fidelização e por fim apresentar os resultados obtidos através da pesquisa. Este estudo se justifica pela crescente competitividade no setor supermercadista e a mudança nas relações de consumo que deixaram os clientes mais conscientes de suas opções de compra no mercado.

Para um melhor entendimento, este artigo irá abordar: A definição de planejamento estratégico, a fidelização de clientes, clientes e comportamento do consumidor.

\section{Fundamentação Teórica}

\section{Planejamento Estratégico}

O planejamento é uma ferramenta essencial dentro da organização, pois através dela são traçadas metas que a empesa deve alcançar e principalmente os meios mais eficazes para alcançar tais metas. O planejamento nada mais é do que o ato de traçar caminhos que levem a empresa ao seu melhor cenário. (FIGUEIREDO, 2006).

O autor Orlickas (2010) defende que o planejamento é a ferramenta de gestão empresarial mais importante para a organização pois a mesma permite que a empresa se prepare para cenários futuros e através disso tome decisões mais assertivas a respeito de seus objetivos.

De acordo com Lacombe (2009) o ato de planejar auxilia a organização no momento de se dar uma direção aos propósitos da empresa, pois a sua utilização mostra aos gestores por quais caminhos a empresa percorreu e através disso concilia qual o melhor caminho que a empresa deve percorrer com os objetivos empresarias daqueles que a compõe.

Conforme Oliveira (2009) as empresas utilizam o planejamento em busca de melhor alcançarem seus objetivos, para isso as empresas deveram passar por duas etapas afim de elaborar um planejamento eficaz, são elas: a análise do ambiente e o estabelecimento de um plano de negócio.

Outro ponto que Oliveira (2009) trata é sobre a estratégia que segundo ele, é a ação realizada com o intuído de se alcançar objetivos, desafios e metas estabelecidas pela empresa de maneira diferenciada, fazendo com que a mesma esteja sempre em melhor posicionamento. 
Em contrapartida os autores Ansoff e McDornnell (1993), acreditam que a estratégia funciona como um conjunto de regras que auxiliam e orientam a organização em qual comportamento aderir. Dessa forma os administradores terão embasamento para a tomada de decisão. A estratégia é o comportamento da empresa que tem como objetivo a busca por um diferencial competitivo. Para o mesmo, a empresa apenas possui um diferencial competitivo sustentável, quando possui estratégias que não podem ser copiadas pelos concorrentes (SANTOS et. Al, 2007).

Após a análise dos temas acima, é necessário analisar o planejamento estratégico que segundo Las Casas (2015), é a forma que a empresa utiliza para alcançar as metas que foram traçadas por ela nos primeiros momentos do planejamento. De acordo com Mintzberg (2004) para que a empresa possua um futuro promissor e alcance o sucesso é necessária a utilização de planejamento, pois o mesmo irá auxiliar na coordenação e no controle das atividades realizadas na organização. Rasmussen (1990) acredita que a utilização do planejamento estratégico, ajuda as empresas a direcionar suas decisões tornando-as dessa forma mais eficientes.

Para Kotler (1992) o planejamento estratégico pode ser definido como um processo gerencial que busca adequar e manter um parâmetro entre os objetivos e os recursos da empresa, a execução de um planejamento estratégico possibilita a empresa diversas melhorias em seus processos diários, em especial a fidelização de clientes. Com um planejamento eficaz a empresa poderá traçar estratégias que visem não só a captação de novos clientes, como também a fidelidade dos atuais. Na próxima seção será abordado justamente essa temática relacionada à fidelização de clientes.

\section{A Fidelização de Clientes}

A palavra fidelidade vem do Latim "fidem" e significa afeição entre sujeitos, a fidelização é o processo usado pelas empresas como forma de estratégia e que visa identificar e amplifica o interesse dos clientes pela marca que está sendo ofertada (BARLOW,2001).

De acordo com Ward e Danger (2007), o processo de fidelização do cliente auxilia para que esse indivíduo perceba a qualidade envolvida no processo de venda, essa percepção ajuda 
a empresa a criar um forte vínculo de lealdade com seu público alvo e consequentemente aumenta seu valor no mercado.

Para Griffin (2009) existem diversos graus de fidelidade entre o cliente e a empresa , na colocação mais baixa está a categoria "nenhuma fidelidade" onde o cliente não se apega a nenhuma marca de forma especifica por estar procurando exclusivamente pelo baixo custo de um determinado produto, essa é a forma de fidelização encontrada em supermercados, já que os clientes se tornam sazonais de acordo com as promoções que o estabelecimento oferece.

Na concepção de Gonçalves (2007) o processo de fidelização auxilia tanto o consumidor quanto o estabelecimento. Os dois caminham juntos na facilidade no momento da compra, isso acontece porque os clientes fiéis não demonstram dificuldade na hora da venda pois já estão certos do que desejam levar para casa, além disso outra vantagem que pode ser vista é o baixo valor com marketing que será empregado, visto que o cliente verá o processo de compra naquele determinado lugar um habito.

Segundo Santos (2008) a fidelização do cliente se torna mais rentável do que a conquista por novos, isso porque na busca por novos clientes a empresa utiliza alto custo com marketing enquanto a manutenção de um público alvo se torna mais eficaz e não exige da empresa gastos muito elevados. Entretanto isso não significa que a empresa deva abandonar totalmente a prospecção de novos negócios.

Como demonstrado ao decorrer desta seção, é possível visualizar a importância de um bom processo de fidelização, através do mesmo a empresa será capaz de crescer sem a necessidade de captação de novos clientes constantemente, entretanto esse processo so poderá ser bem executado caso a empresa saiba qual o seu publico alvo e dessa forma definir o tipo de desejo cada cliente possui. A fidelização é um importante elemento de marketing estratégico visto ser reconhecida a associação entre fidelização do cliente e rentabilidade para a empresa. Existe forte ligação entre satisfação do cliente, a sua retenção e o resultado materializado em proveitos para a empresa. O gráfico 01 apresenta porque é que os clientes fidelizados são mais rentáveis (REICHHELD, F. 1996). 
Gráfico 01: Porque é que os Clientes Fidelizados são mais Rentáveis.

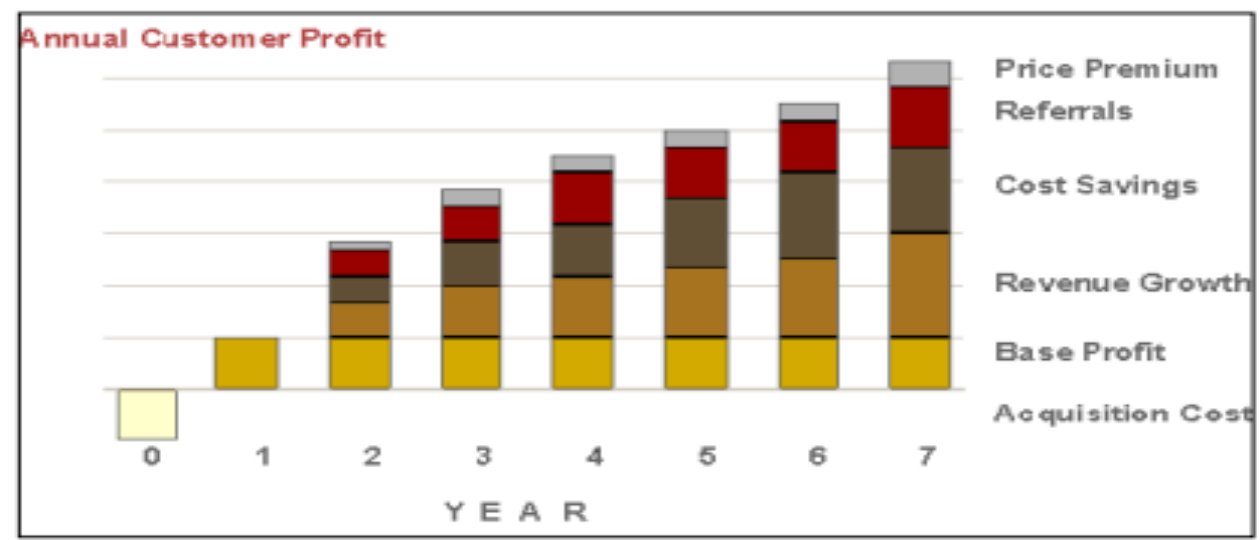

Fonte: Reichheld, (1996).

Pode se observar através da demonstração gráfica a rentabilidade proporcionada por clientes fiéis: A seguir segue a descrição apresentado no gráfico 01.

- Custo aquisição (acquisition cost): investimento inicial de toda a empresa para atrair novos clientes (publicidade, comissão de vendas, avaliação de crédito, etc.);

- Lucro básico (base profit): constante ao longo do tempo, quanto mais tempo a empresa mantiver o cliente, mais ganhará nesse item;

- Aumento da receita por cliente (revenue growth): na maioria das empresas, os gastos do cliente tendem a se acelerar com o tempo;

- Economias de custo operacional (cost savings): à medida que os clientes estão mais familiarizados com o negócio e o produto, os clientes tendem a ser mais eficientes, menos dependentes do suporte da empresa;

- Referências (Referrals): clientes satisfeitos recomendam a empresa a outras pessoas ou empresas;

- Preço diferenciado (Premium Price): na maioria dos sectores, os clientes mais leais estão dispostos a pagar um preço Premium em média 20\% superior pela marca de sua preferência, comparativamente aos novos clientes.

Desta forma, é possível compreender a importância da fidelização do cliente para uma organização. Já Moura et al. (2002) afirma que a lealdade, recompra e indicação da empresa para outros consumidores potenciais. 


\section{Clientes}

Afim de se melhor estabelecer estratégias é necessário que a empresa conheça em seus clientes, identificando suas necessidades e traçando meios para que seja possível atender essas necessidades sem afetar o rendimento da empresa, clientes são todos aqueles que adquirem e fazem uso dos produtos da empresa (MOURA, 2009).

Segundo Whiteley (1999) saber definir os clientes é o principal ponto de sucesso da empresa é a sábia definição de quem são os clientes a quem a mesma deseja atender, para isso é preciso identificar quais os principais tipos de clientes que a empresa deve possuir. São eles: os clientes finais, são aqueles que irão o utilizar o produto da empresa, ou seja, os consumidores; os clientes intermediários que sã formados pelos distribuidores e revendedores que tornam disponível o produto para o cliente final e por fim os clientes internos que são responsáveis por servir os clientes finais e os intermediários.

Para Gupta e Lehmann, (2003) o valor que um cliente traz para a empresa não é apenas limitado ao lucro em cada transação, mas é o total dos lucros que ele pode trazer ao longo da sua relação com a empresa. Os clientes são por isso bens intangíveis, ou seja, é difícil estabelecer um valor para estes bens.

Outro aspecto que necessita ser estudado é o ciclo de vida do cliente que abrange o processo pelo qual esse cliente passa. Isso inclui seu histórico de consumo, entre outros aspectos, descobrir o atual estágio desse cliente em seu ciclo de vida ajuda a empresa a traçar estratégias certeiras para esse indivíduo (GREENBERG, 2011).

Conforme Juran (1995) a descoberta sobre o tipo de cliente que a empresa está atendendo auxilia a organização sobre as estratégias que a mesma irá utilizar, pois dessa forma a empresa poderá tomar decisões certeiras e atingir seu público alvo com maior facilidade.

De acordo com Kumar (2008) o ciclo de vida de um cliente auxilia o gestor tomar decisões estratégicas com maior segurança. A figura 1 demonstra de forma clara o momento em que o gestor (t) deve tomar decisão de gestão relativamente a este cliente, essa decisão é tomada com base no valor histórico do cliente, ou no valor futuro do mesmo. Como em qualquer tipo de relação as relações clientes/empresa evoluem ao longo do tempo. Prospectos, novos compradores e compradores de longa data não têm as mesmas necessidades, e as suas relações com a empresa mudam, assim como mudam as suas expectativas e comportamentos. 
Figura 01: Ciclo de Vida de um Cliente.

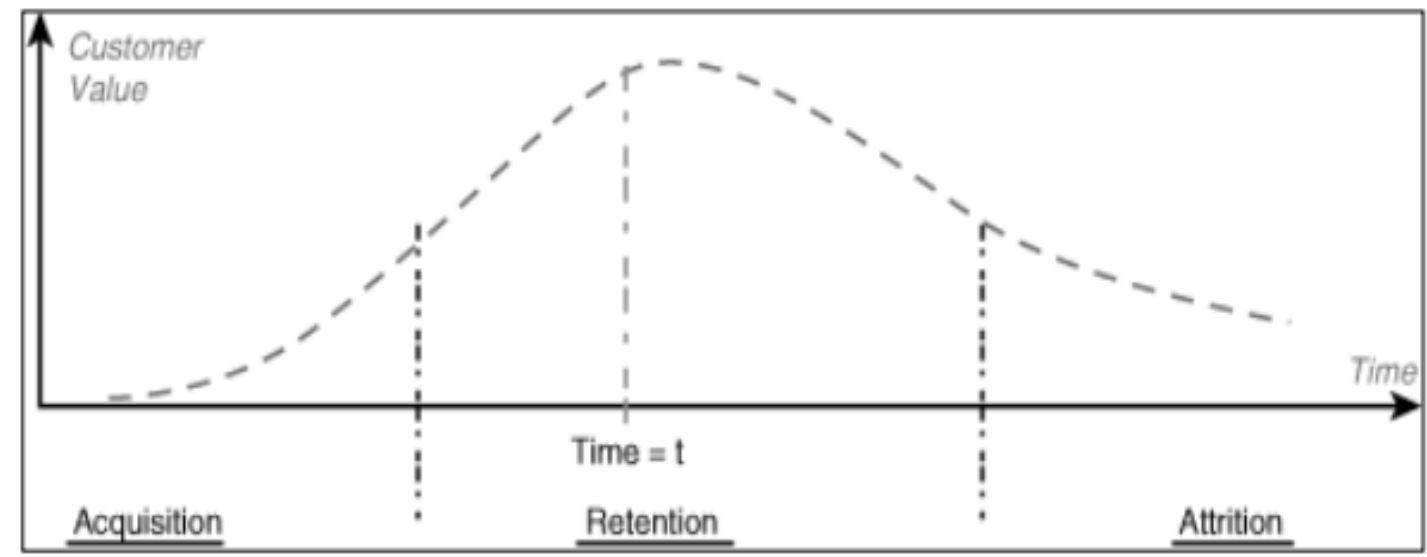

Fonte: Kumar (2008).

O conceito de ciclo de vida providencia um enquadramento apropriado para compreender e gerir estas diferenças (BLATBERG et al. 2001).

Outro fator a ser analisado sobre o publico alvo é o estágio de vida do consumidor, todo individuo possui necessidades, porém, essas necessidades mudam de acordo com a idade do mesmo, o estágio da vida do consumidor é fator determinante naquilo que ele deseja adquirir (SOLOMON, 2009).

Saber definir o tipo de cliente que a empresa deseja alcançar é fundamental, através disso a organização traçará estratégias certeiras para alcançar seu publico alvo, entretanto para definir o tipo de cliente e com isso as suas necessidades, é importante fazer uso de estudos relacionados ao comportamento do consumidor.

\section{Comportamento do Consumidor}

O comportamento do consumidor é considerado o estudo que busca avaliar os processos envolvidos em determinado indivíduo ou grupo que selecionam e adquirem produtos ou serviços buscando satisfazer seus desejos e necessidades. Através desse estudo é possível identificar de qual maneira o consumidor irá se comportar ao presenciar diversos tipos de 
marketing, e com isso é possível que uma empresa consiga melhor posicionar seu produto no mercado (SOLOMON, 2016).

Solomon (2016) afirma que cada consumidor é diferente, entretanto existem semelhanças em seus desejos e necessidades que permite com que sejam categorizados em um determinado seguimento, dessa forma é possível identificar qual o tipo de produto é mais adequado para se oferecer a um cliente.

Na concepção de Merlo (2014), no intuito de demonstrar de maneira pratica como funciona o comportamento do consumidor, elaborou um esquema com todos os fatores que influenciam o comportamento de compra de um cliente. Para um melhor entendimento a figura 3 ilustra os fatores que influenciam o comportamento de compra (MERLO, (2014).

Figura 02: Fatores que Influenciam o Comportamento de Compra

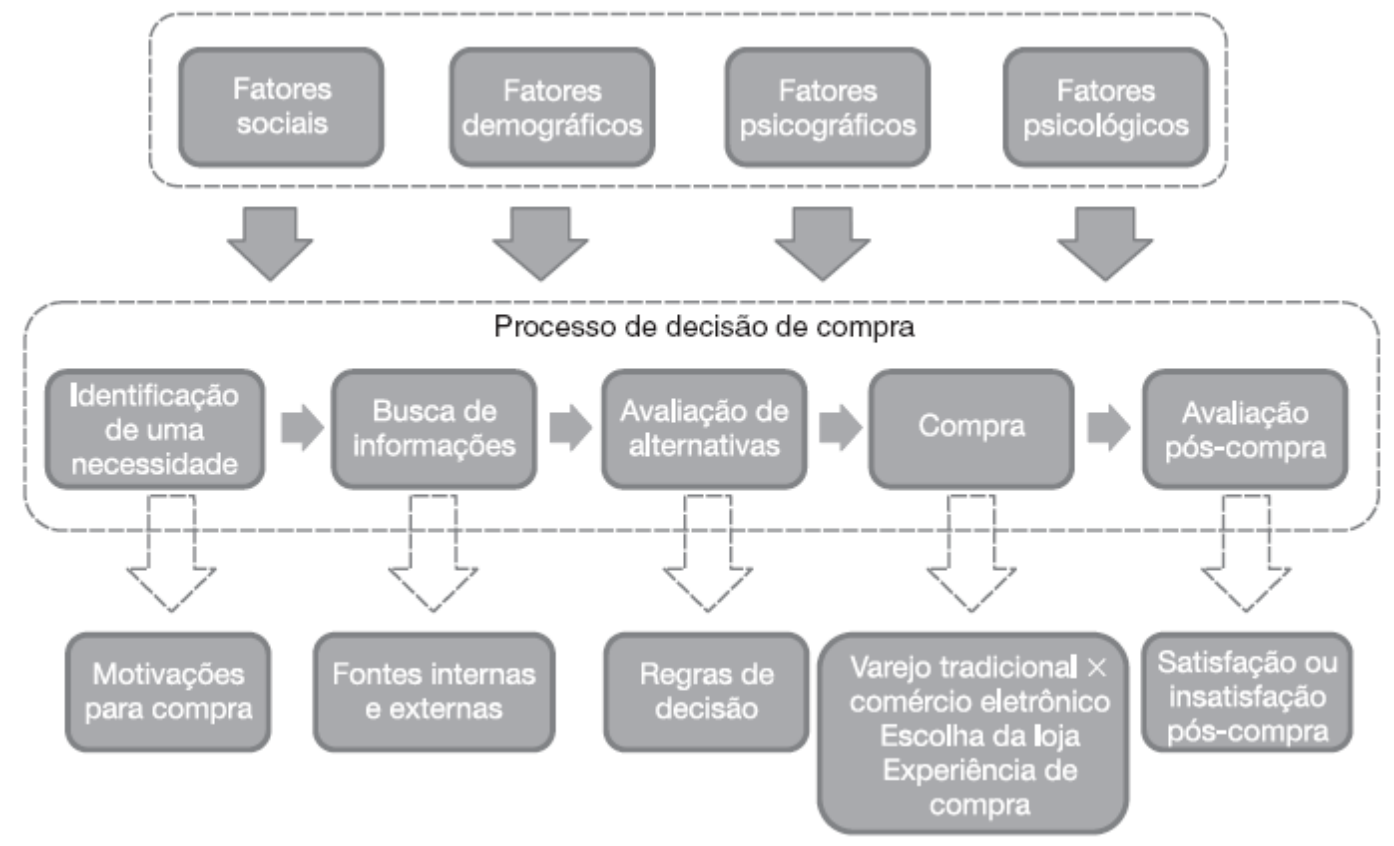

Fonte: Extraído de Merlo (2014).

Cada motivação possui uma reação, dessa forma é possível inferir que conhecer profundamente os clientes é importante, pois através desta ferramenta a empresa pode melhor conhecer o consumidor e com isso aprimorar suas estratégias para alcançar seu público alvo. 
Para se estudar os aspectos do comportamento do consumidor é necessário que seja realizada uma análise na motivação de cada indivíduo. De acordo com Karsaklian (2012), cada indivíduo vive sua vida de forma natural, entretanto em um determinado momento ele será afetado por um desconforto, esse desconforto fará com que o mesmo crie a necessidade de obter algo que o livre desse problema e a partir disso buscará por um produto, essa necessidade que o indivíduo sente é considerada como uma motivação.

Existe também outro fator que a cada dia se torna determinante para a empresa obter o sucesso, no momento em que a organização estiver elaborando o seu planejamento estratégico e necessitar traçar o seu público alvo, é importante definir o gênero desse indivíduo, $80 \%$ das compras são realizadas ou influenciadas por mulheres (JOHNSON, LEARNED, 2012).

O estudo realizado acerca das motivações existente nos atos dos consumidores é muito importante, pois possibilita a empresa a traçar estratégias que venham a suprir a necessidade mercadológica existente (KARSAKLIAN, 2012).

\section{Métodologia}

Na elaboração deste artigo optou-se por um estudo de opinião pública que de acordo com Lima (2017) é um levantamento estatístico de uma amostra particular da opinião pública, que são realizadas para representar as opiniões de uma população fazendo-se uma série de perguntas a um número de pessoas e então extrapolando as respostas para um grupo maior dentro do intervalo de confiança. No âmbito organizacional, a pesquisa de opinião é considerada o melhor caminho para se conhecer a opinião dos públicos de interesse da organização a respeito de determinado tema. Segundo Kunsch (2002, p.289), "a pesquisa de opinião se constitui em um dos tipos de pesquisas mais relevantes para a área de relações públicas" e pode ser realizada para se analisar as "relações com os empregados, consumidores, acionistas, revendedores, comunidade, imprensa, poderes públicos”.

Para fundamentação teórica foi realizado um levantamento em fontes bibliográficas, em livros, revistas e artigos. Este artigo é de cunho quantitativo, que de acordo com Fonseca (2002) a pesquisa quantitativa centra-se na objetividade e com seu uso é possível analisar uma grande 
quantidade de informações de forma simplificada. Com abordagem exploratória e descritiva conforme Selltiz et al. (2013) a pesquisa exploratória é destinada para pesquisadores que buscam por ideias ou intuições que possam atestar o que se está sendo pesquisado. Na pesquisa descritiva, Vergara (2000) argumenta que essa forma de pesquisa expõe as características de uma população estabelecendo correlações e definindo sua natureza. Para realização da pesquisa em campo foi utilizado um instrumento contendo 10 questões com alternativas fechadas. Foi analisado uma amostra composta de 100 (cem) indivíduos, no período de 01 a 15 de outubro de 2018. A pesquisa foi realizada em lugares públicos como ruas, praças e parques da cidade de Brejo Santo-CE.

O processo de amostragem escolhido foi o acidental. Conforme Martins (1994, p.40) trata-se de uma amostra formada por aqueles elementos que vão aparecendo, que são possíveis de se obter até completar o número de elementos da amostra. Geralmente utilizada em pesquisas de opinião, em que os entrevistados são acidentalmente escolhidos.

Segundo os autores Schiffman e Kanuk (2015) a escolha pela amostra não probabilística é indicada para pesquisadores que não possuem a oportunidade de avaliar a amostra inteira.

Após a coleta das informações, os dados foram tabulados e tratados pelo software Excel apresentado em formato de gráficos e analisados de acordo com a fundamentação teórica exposta neste artigo. Essa análise confrontará a realidade teórica exposta pelos autores citados neste estudo com a realidade encontrada pelo pesquisador em campo, podendo assim gerar uma nova compreensão de conhecimentos científicos.

\section{Análise e Discussões de Resultados}

A coleta dos dados desta pesquisa foi realizada no período de 01 a 15 de outubro de 2018, através de aplicação de questionários estruturados com 10 ( dez) perguntas fechadas a uma amostra de 100 ( indivíduos) que estavam localizados em lugares públicos como ruas, praças e parques da cidade de Brejo Santo-CE.

Os dados obtidos através da pesquisa foram possíveis identificar diversos aspectos dos consumidores de Brejo Santo-CE. A Partir desses aspectos, foi possível identificar dimensões de satisfação dos clientes, características dos consumidores entre outras variáveis. De maneira geral 
é possível identificar que os clientes dos mercantis de Brejo Santo, CE possuem idade variante entre 18 e 46 anos.

Em sua grande maioria são moradores da cidade de Brejo Santo, CE e por isso escolhem esta cidade para efetuar suas compras de forma mensal, além disso os mesmos veem a excelência no atendimento como fator primordial para permanecerem consumindo em determinado mercantil.

Gráfico 02: Gênero e Idade dos Entrevistados.

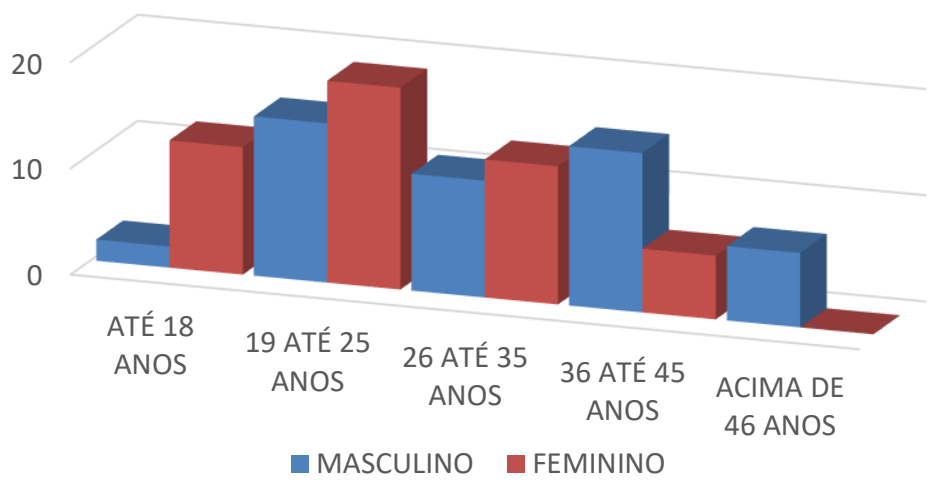

Fonte: Dados da pesquisa (2018).

O gráfico 02 demonstra o gênero e a idade dos respondentes, de acordo com os resultados é possível verificar que a maior concentração de respondentes são mulheres de até 35 anos, esse acontecimento pode ser explicado devido ao fato de que as mulheres compram mais ou influenciam na compra de $80 \%$ dos bens de consumo (JOHNSON, LEARNED, 2012). Outro dado interessante é o fato de que homens com idade superior a 35 anos serem predominantes nessa questão, simbolizando uma possível mudança de hábitos, desde muito tempo é comum que as mulheres sejam responsáveis pelas compras da casa, entretanto como pode ser visto essa prática vem mudando, esse fato demonstra a necessidade das empresas pensarem em estratégias que visem alcançar o gênero masculino. 


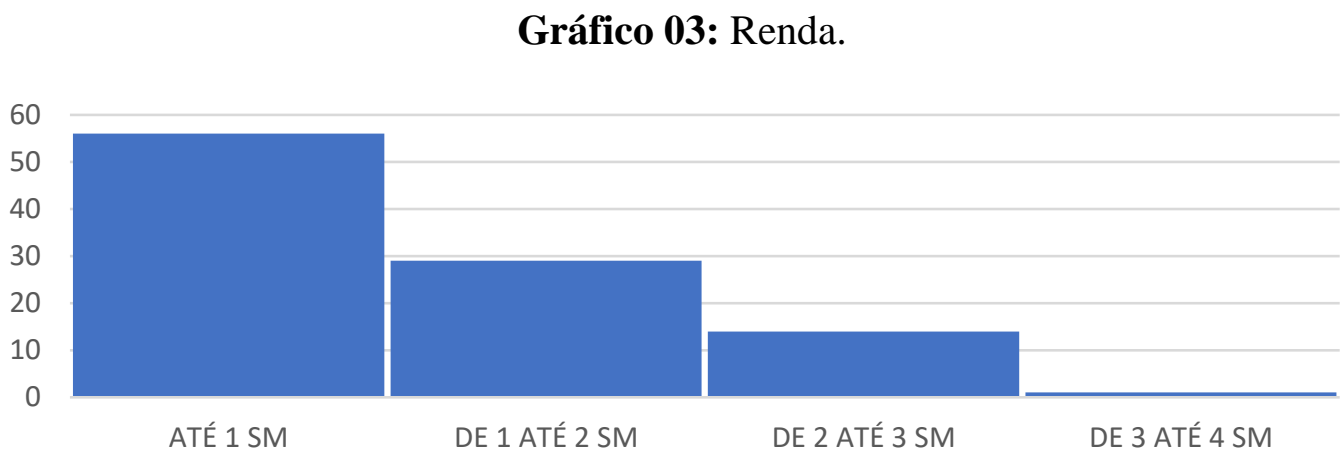

Fonte: Dados da pesquisa (2018).

A segunda pergunta do questionário buscou identificar qual a renda dos entrevistados, no gráfico 03 acima é possível identificar que o maior volume de pessoas cerca de $56 \%$ dos respondentes ganha no máximo dois salários mínimos. Esse dado determina a classe social dos clientes, como pode ser visto a grande maioria dos respondentes pertence à classe social $\mathrm{E}$, em posse dessa informação as empresas podem identificar se seus preços correspondem com a real capacidade de compra de seus clientes e com isso aumentar o número de consumo e consequentemente diminuir possíveis produtos encalhados no estoque.

Gráfico 04: Cruzamento das Variáveis de Renda e Gênero.

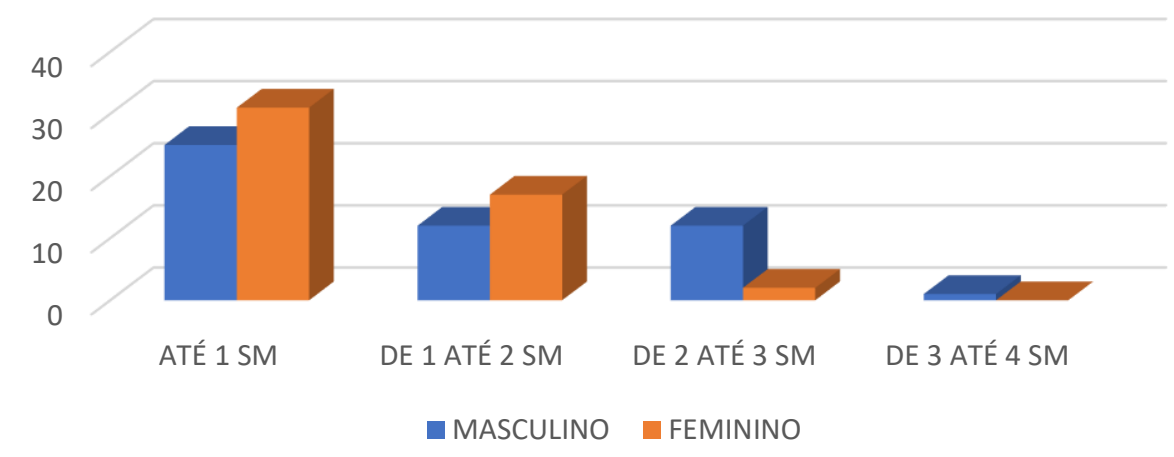

Fonte: Dados da pesquisa (2018).

O gráfico 04 apresenta resultados de uma análise envolvendo o cruzamento das variáveis renda e gênero, como pode ser visualizado no gráfico 3 acima as maiores rendas são do gênero masculino, esse dado se torna notório na terceira barra (2 salários mínimos até 3 
salários mínimos). Esses dados reflete uma pesquisa realizada pelo Instituto Brasileiro de Geografia e Estatística- IBGE (2018) que comprovou que as mulheres mesmo com ensino superior completo ganham menos que homens. A pesquisa foi realizada com a população brasileira com mais de 25 anos que tenha concluído o ensino superior até 2016, de acordo com a mesma 23,5\% das mulheres são formadas enquanto os homens correspondem a 20,7\%, entretanto as mulheres ganham em media $75 \%$ do que o sexo oposto ganha, dessa forma em uma escala básica se um homem ganhasse R\$ 1.000,00 uma mulher ganharia R \$750,00.

Gráfico 05: Cruzamento das Variáveis Idade e Renda.

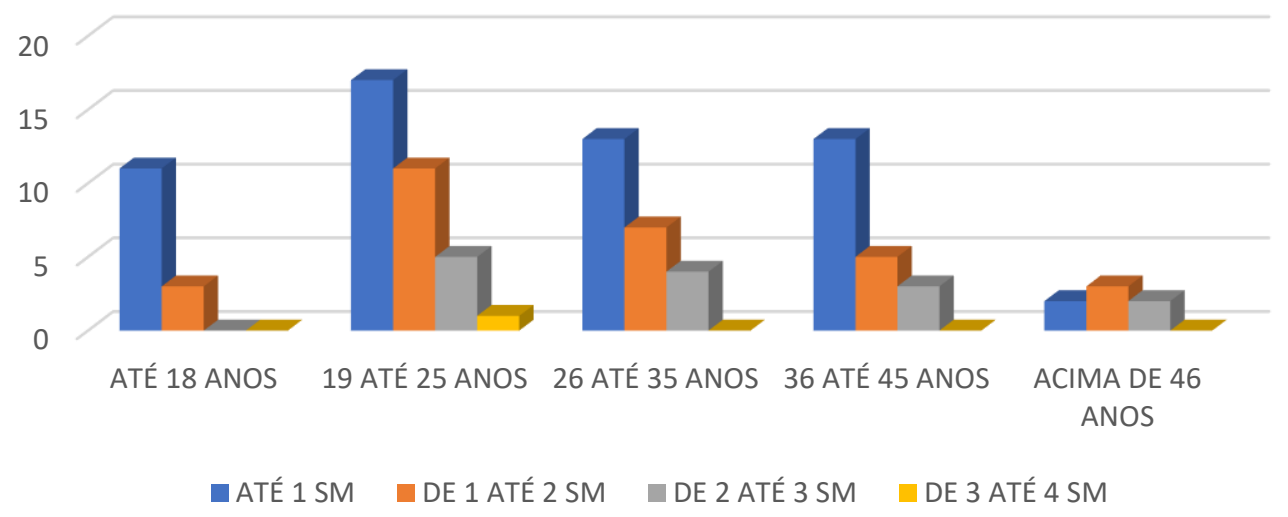

Fonte: Dados da pesquisa (2018).

O gráfico 05 representa o cruzamento entre as variáveis idade e renda, como pode ser visualizado a renda dos indivíduos muitas vezes tende a aumentar de acordo com sua idade, dessa forma pessoas mais maduras ganham um pouco a mais do que jovens.

Isso está diretamente relacionado ao comportamento do consumidor, pessoas com mais idade possuem mais experiencia de vida e consequentemente possuem necessidades fixas, como foi dito por Solomon (2009), a cada estágio de vida o indivíduo vai criando necessidades diferentes, a pesquisa demonstra que o maior número de pessoas pesquisadas estão na faixa etária entre 19 a 25 anos, dessa forma é importante que os mercantis de Brejo Santo, CE estejam preparados para acompanhar o comportamento desses consumidores mais jovens. O processo de fidelização só é eficaz se o cliente encontrar na loja mais do que uma mera necessidade, é 
necessário que as empresas tenham em mente os desejos, sonhos e inquietações dessa nova geração de cliente.

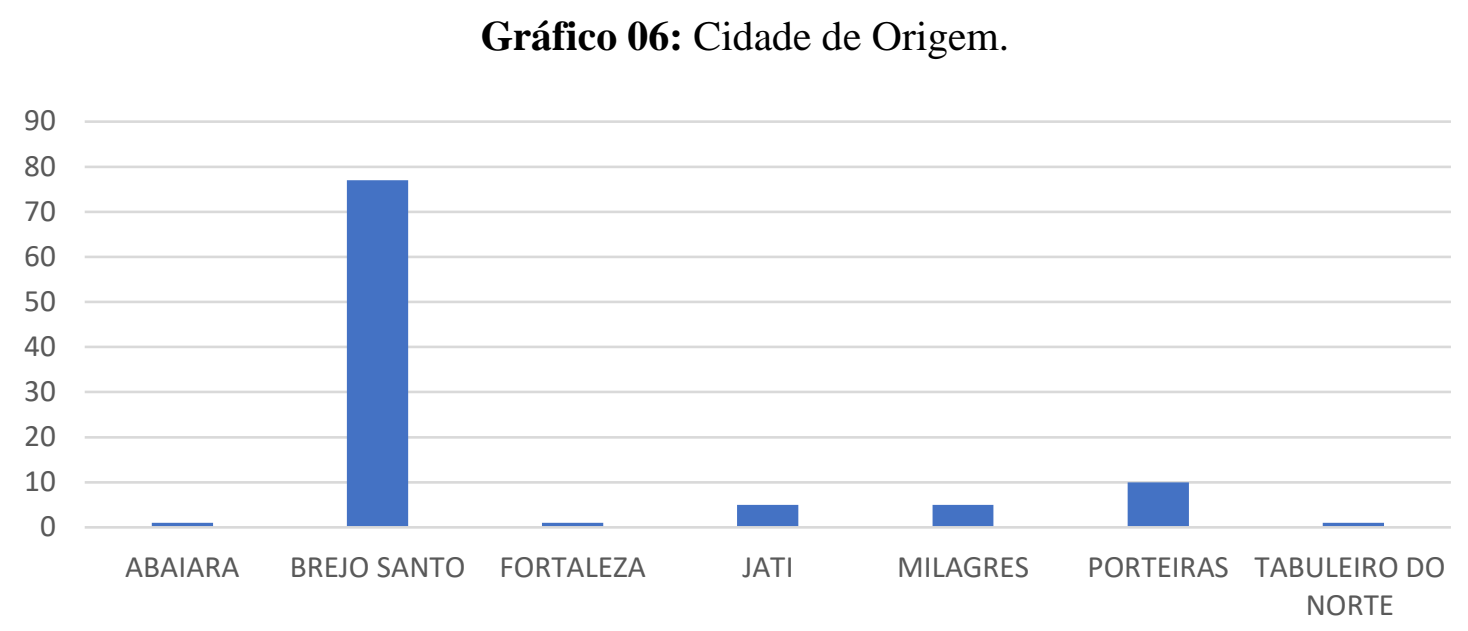

Fonte: Dados da pesquisa (2018).

O gráfico 06, demonstra que a grande maioria dos entrevistados são da cidade de Brejo Santo-CE, esse fato pode ser compreendido por que os consumidores buscam por comodidade, dessa forma viajar até outro município se torna cansativo. Entretanto um fato interessante e que cerca de $23 \%$ dos respondentes afirmam morar em outra cidade, isso pode ocorrer devido ao fato de o município com o passar dos anos vir se tornando um polo comercial e referencia em prestação de serviços.

Com isso é possível inferir que esses respondentes não se deslocaram até a cidade exclusivamente com o intuito de comprar em mercantis localizados no município, mas com o intuito de usufruir de outro serviço, dessa forma a renda dos mercantis de Brejo Santo-CE é derivada em parte de moradores de outra cidade.

O Gráfico 07, na sequência, buscou identificar a frequência das compras dos indivíduos, como pode ser visualizado a grande maioria, cerca de $44 \%$ da amostra compra nos mercantis mensalmente, seguido por $19 \%$ que compra de duas a três vezes por semana, $16 \%$ que consome quinzenalmente, $15 \%$ que frequenta diariamente e apenas $6 \%$ que afirmam frequentar raramente estes estabelecimentos. 
Gráfico 07: Frequência de Compra.

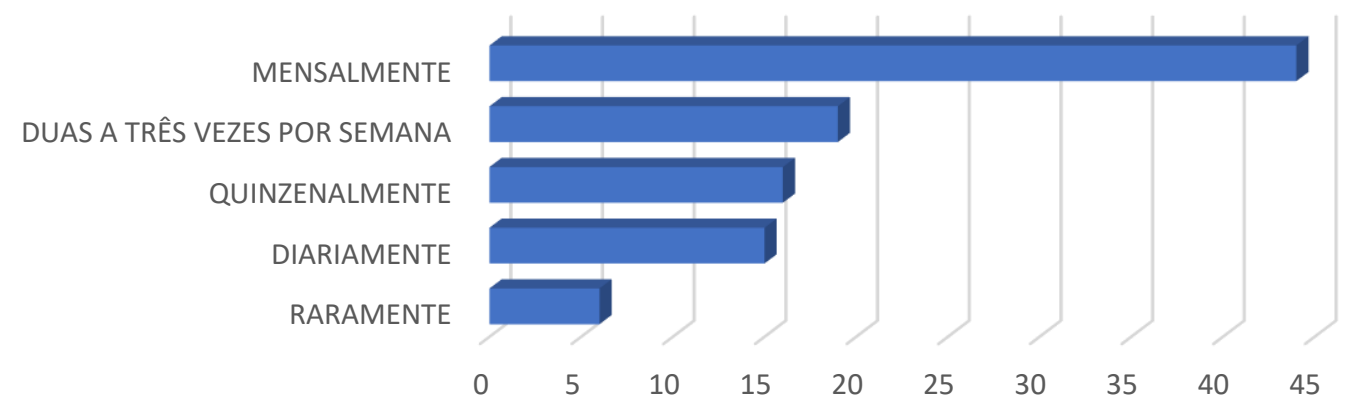

Fonte: Dados da pesquisa (2018).

Através destes dados é possível identificar a precisão das respostas obtidas já que cerca de $94 \%$ dos entrevistados frequenta estes estabelecimentos de maneira assídua e dessa forma possui um nível aceitável de propriedade naquilo que está afirmando. Os motivos que levam esse consumidores a frequentar o estabelecimento uma vez por mês, pode estar relacionado aos dados do gráfico 03 , onde $85 \%$ dos consumidores afirmam receber no máximo dois salários, consequentemente as condições salariais reduz o puder de compra.

Entretanto existe outro fator que merece destaque, os mercantis estão satisfeitos com esse fluxo de compras? será que os gestores desses mercantis possuem alguma estratégia baseada no ciclo de vida do cliente? Ou será que são desconhecedores dos comportamentos e características de seus clientes. Para que a empresa permaneça ativa no mercado e com condições financeiras para se manter é importante que o consumo dos clientes seja recorrente, dessa forma o ideal é que os consumidores frequentem os mercantis de maneira assídua, para isso a empresa deve investir em meios de fidelização.

O gráfico 08 a seguir, demonstra os resultados sobre os fatores que influenciam um cliente a deixar de comprar em um mercantil, como pode ser visualizado no gráfico acima a opção que obteve o maior número de respostas é ao fato de o estabelecimento oferecer um atendimento ruim ( $48 \%$ das respostas). Kotler (2000), afirma que o mercado atualmente se encontra em um estado de competitividade acirrada e devido a isso é necessário que a empresa ofereça diferenciais, tais como a qualidade no atendimento. 
Gráfico 08: Fatores que Influenciam Deixar de Comprar em um Mercantil.

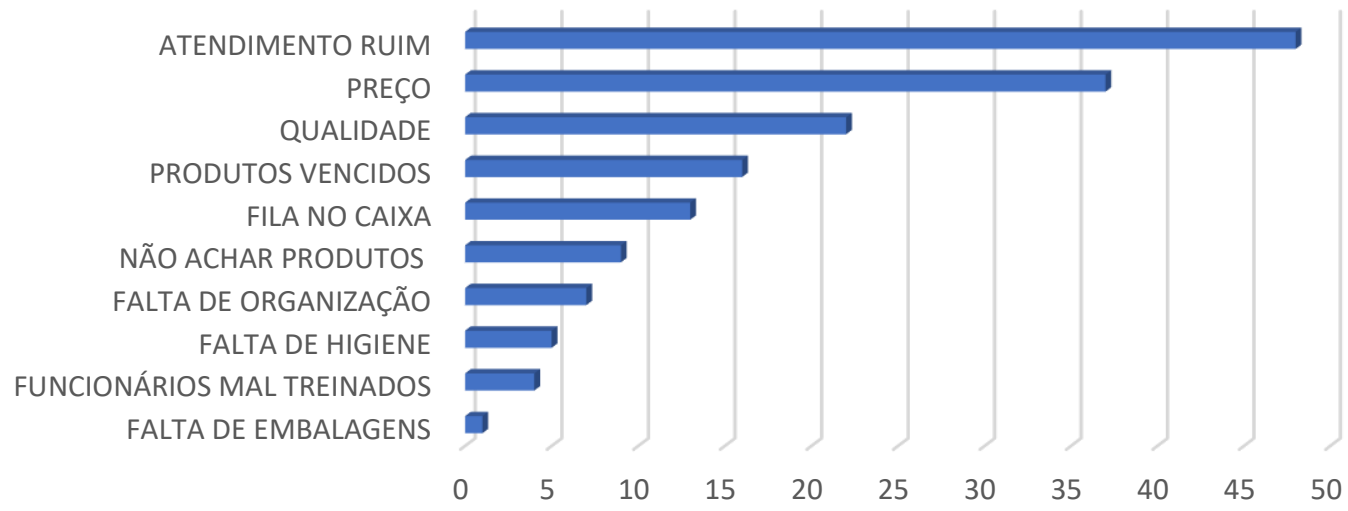

Fonte: Dados da pesquisa (2018).

No gráfico 08 demonstra a necessidade de investimento na capacitação dos funcionários, oferecer um atendimento de qualidade é essencial para uma empresa, através disso é possível por em pratica qualquer estratégia que vise a fidelização de um cliente Kotler (2001) explica que a procura por novos clientes é cansativa e onerosa, por esse motivo manter um cliente se torna muito mais viável para uma empresa.

Essa questão traz à tona o real significado de fidelização de clientes, pois sabendo o que espanta um cliente é possível identificar pontos que o fazem se sentir bem dentro de uma empresa e através disso é possível direcionar todos os esforços da organização para satisfazer as necessidades de seus clientes e consequentemente faze-lo frequentar a empresa frequentemente.

O próximo gráfico (09) demonstra as respostas obtidas para a oitava pergunta do questionário, na mesma os respondentes foram questionados se haveria alguma sugestão de melhoria para os mercantis que os frequentam. Das sete opções dadas a que obteve o maior numero de resposta foi a possibilidade de os mercantis oferecerem aos seus clientes um caixa para pagamento de contas como água, luz e telefone. Através dessa resposta é possível visualizar a necessidade dos clientes em obter comodidade, de acordo com Alencar (2009), a comodidade se tornou um diferencial competitivo obrigatório nas empresas que desejam obter e reter clientes, a comodidade consiste no ato de fazer determinada atividade se tornar cômoda. 
Gráfico 09: Sugestões de Melhorias nos Mercantis.

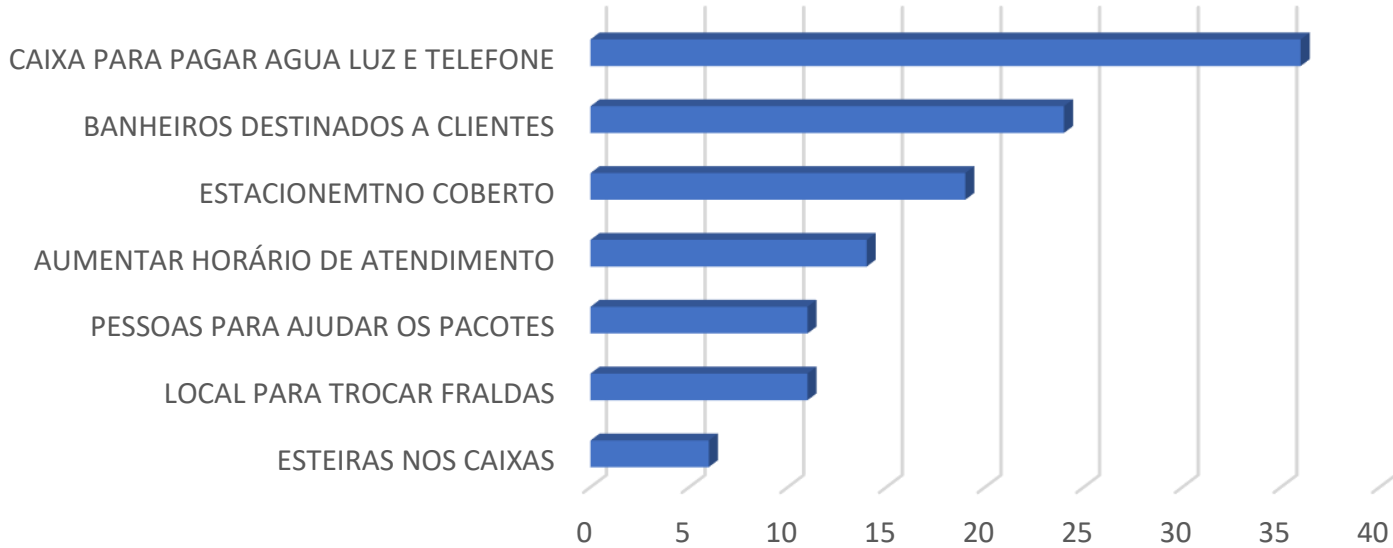

Fonte: Dados da pesquisa (2018).

Essa resposta sugere um novo padrão para o comportamento do consumidor onde o mesmo passa a exigir das empresas a satisfação de todas as suas necessidades em apenas um ambiente. Um exemplo claro disso é a necessidade de haver uma praça de alimentação em mercantis, onde os consumidores iriam para comprar seus produtos e aproveitariam a ocasião e o espaço para passar um momento de lazer com a pessoa que o está acompanhando ou até mesmo sozinho. O gráfico 09 ainda apresenta sugestões de mudanças como (banheiros, estacionamentos cobertos, maior flexibilidade de horário, auxiliares nos pacotes, fraldários) isso prova que o cliente de ontem não é o mais de hoje, e nem será mais o de amanhã. As empresas têm que se atentar com as novas necessidades de seus clientes.

Gráfico 10: Motivos de Escolher Determinados Mercantis da Cidade.

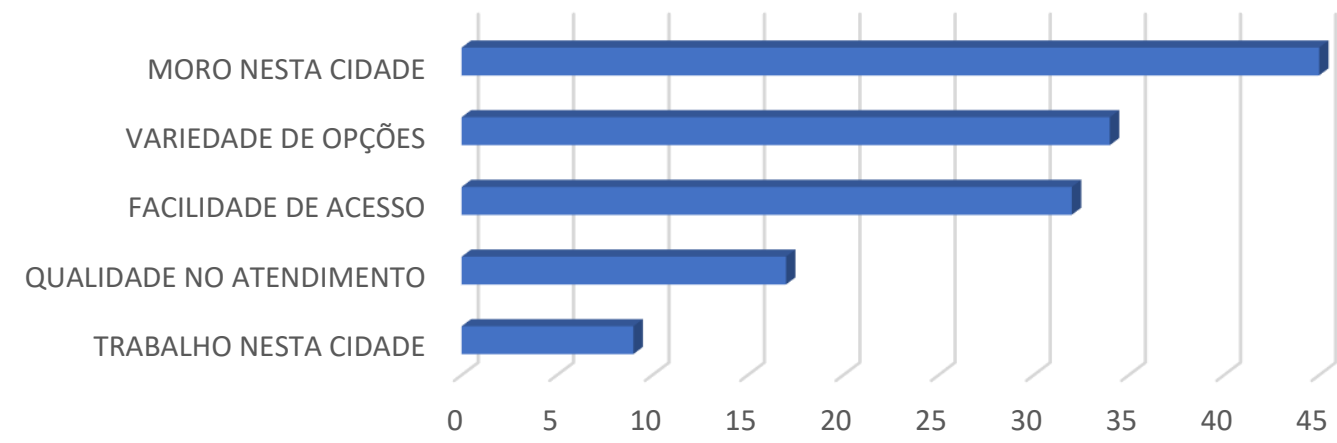

Fonte: Dados da pesquisa (2018). 
O gráfico 10 apresentam os motivos que levam os respondentes a comprarem em mercantis da cidade de Brejo Santo-CE, 45\% dos respondentes afirmam escolher mercantis deste município devido ao fato de morarem no mesmo, a segunda opção mais abundante (34\%) é a variedade de opções existentes em Brejo Santo, seguido pela facilidade de acesso (32\%), qualidade no atendimento (17\%) e por fim ao fato de alguns respondentes trabalharem na cidade $(9 \%)$.

Entretanto é importante analisar alguns dados importantes que estas respostas trazem, o primeiro é o fato de que os indivíduos estão realmente preocupados com a comodidade dessa forma permanecem comprando em estabelecimentos de Brejo Santo, o segundo fato a ser analisado é a importância de as empresas investirem em opções de produtos. Um fato interessante é que o gráfico 7 demonstrou que o principal fator que o faria desistir de comprar em um mercantil seria o atendimento ruim, entretanto nesta pergunta a qualidade no atendimento recebeu apenas $17 \%$ das escolhas. Esse fato pode demonstrar que para um cliente a qualidade no atendimento não é visto como um diferencial, mas sim como uma obrigação do estabelecimento.

Gráfico 11: Avaliação dos Estabelecimentos da Cidade de Brejo Santo-CE.

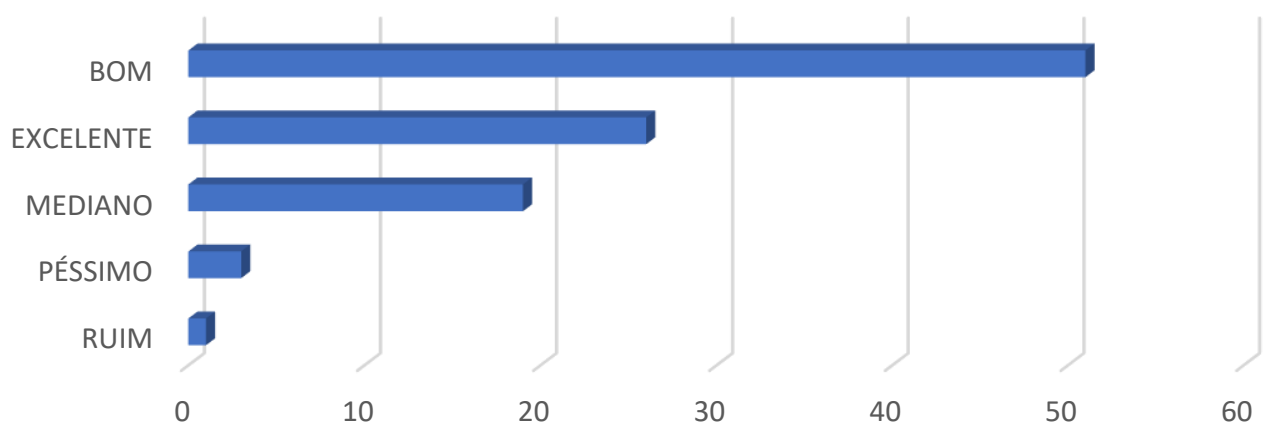

Fonte: Dados da pesquisa (2018).

Por fim o gráfico 11 trata-se de uma avaliação sobre $\mathrm{o}$ atendimento dos estabelecimentos localizados em Brejo Santo-CE, na pergunta os mesmos deveriam avaliar entre bom, excelente, mediano, péssimo e ruim. Como pode ser observado a grande maioria das respostas, cerca de 51\% avaliou os estabelecimentos com "bom" enquanto a minoria (apenas 1 pessoa) avaliou os estabelecimentos como "ruim".

815 Id on Line Rev. Mult. Psic. V.12, N. 42, p. 797-819, 2018 - ISSN 1981-1179 Ediçăo eletrônica em http://idonline.emnuvens.com.br/id 
Através dessas respostas é possível inferir que de um certo modo os mercantis localizados na cidade de Brejo Santo-CE possuem critérios que satisfazem aos seus clientes, dessa forma a sua única preocupação será a de traçar estratégias que façam com que esses indivíduos frequentem o lugar assiduamente.

\section{Considerações Finais}

Diante dos procedimentos teóricos-metodológicos utilizados no presente artigo, conclui-se que se faz necessário o avanço de novas pesquisas sobre estratégias de fidelização de clientes, pesquisa de mercado e a qualidade no atendimento ao cliente na cidade de Brejo Santo - CE. No entanto, foi possível comprovar que a argumentação teórica exposta neste estudo condiz com os resultados obtidos nesta pesquisa.

A pesquisa apresentou uma falha na gestão de políticas estratégicas de fidelização dos clientes por parte dos mercantis da cidade de Brejo Santo - CE. É preciso que os gestores desses estabelecimentos estejam atentos as necessidade e desejos de seus clientes. Reinartz e Kumar, (2002) afirmam que não existe um formula certa de rentabilizar a lealdade de um cliente, pois há várias abordagens e variam de acordo com o negócio, o perfil de cliente e a complexidade dos seus canais de distribuição. Mas, isso não quer dizer que não possa gerir e conquistar o cliente, pois gerir clientes para a lealdade não é a mesma coisa do que gerir para o aumento dos lucros.

O cliente é o principal ativo da empresa, contudo, são poucas as que conhecem este valioso ativo. Confrontando essa abordagem teórica, foi observado no gráfico 6 que a maioria dos clientes dos mercantis da cidade de Brejo Santo - CE frequentam apenas uma vez por mês, o estabelecimento, isso significa uma falta de política estratégica por parte dos gestores desses mercantis. Gupta e Lehmann, (2003) afirma que as empresas só existem se existirem clientes, logo o valor do cliente não é apenas o lucro que este traz à empresa em cada compra, o maior valor é conseguir que este efetue várias compras e que as transações se prolonguem ao longo do tempo.

No gráfico 10, a maioria dos clientes dos mercantis avaliaram o atendimento apenas como bom, ou seja, será que essas empresas procuram aplicar estratégias visando o alcance de 
vantagens competitivas sustentáveis, que lhes possibilitem manter-se e conquistar mais mercados? É preciso que as empresas comecem a entender a necessidade de não olhar apenas para o ciclo de vida dos produtos, mas pensar em ciclo de vida do cliente.

Em se tratando de mudanças no comportamento do consumidor o gráfico 8 apresentou que o cliente de hoje não busca apenas preço e qualidade em serviços e produtos. Para o cliente qualidade e preço é o mínimo que se espera de um produto ou serviço. O cliente mudou, as necessidades são outras, os desejos também. Para uma organização que busca se manter competitiva é preciso investir no cliente através de uma proposta de valor. É importante lembrar que o valor que um cliente traz para a empresa não é apenas limitado ao lucro em cada transação, mas é o total dos lucros que ele pode trazer ao longo da sua relação com a empresa.

\section{Referências}

ANSOFF; H. Igor; ALT, Edward J. MCDONNELL. Implantando a Administração Estratégica. $2^{\text {a }}$ ed. São Paulo: Atlas, 1993.

BARLOW, R. Relationship Marketing - The ultimate in costumer services, ed.4 São Paulo: Atlas, 2001.

BLATTBERG, R. C., Getz, G., and Thomas, J. S. Customer Equity : Building and Managing Relationship as Valuable Assets, Harvard Business School. (2001).

FIGUEIREDO, Sandra. O planejamento estratégico. - 3. ed. 3. reimpr. - São Paulo: Atlas, 2006.

FONSECA, Gustavo. A fidelização como arma estratégica. São Paulo: Atlas, 2002.

GIL, Antonio Carlos. Como elaborar projetos de pesquisa. 4. ed. São Paulo: Atlas, 2008.

GONÇALVES, Carlos Alberto. Marketing de Relacionamento. Database de Marketing: Uma estratégia de adaptação em mercados competitivos. Rio de Janeiro: Axcel Books do Brasil, 2007.

GREENBERG, Paul. CRM na velocidade da luz: conquista e lealdade de clientes em tempo real na internet. Rio de Janeiro: Campus, 2011.

GRIFFIN, Jill. Como conquistar e manter clientes fieis. São Paulo: HSM management, 2009. 
Gupta, S., and Lehmann, D. R. (2003). "Customers as Assets." Journal of Interactive Marketing, 17(1), 9-24.

INSTITUTO DE PESQUISA E ESTRATÉGIA ECONÔMICA DO CEARÁ. Perfil básico municipal 2016: BREJO SANTO. Fortaleza: IPECE, 2016. Disponível em <http://www.ipece.ce.gov.br/perfil_basico_municipal/2016/Brejo_Santo.> Acessado em 27/02/2018 as 20:11.

JURAN , J. M., Planejando para a qualidade. São Paulo: Pioneira, 1995.

KOTLER, Philip. Administração de Marketing: análise, planejamento, implementação e controle. 5a ed. Atlas: São Paulo 2006.

KUMAR, V. (2008). Managing Customer For Profit, Wharton School Publishing.

LAS CASAS, Alexandre Luzzi. Marketing de Nichos. São Paulo: Atlas, 2015.

LACOMBE, Francisco. Teoria geral da administração. São Paulo: Saraiva, 2009.

MAXIMIANO, Antônio. Introdução a administração. 7. ed. São Paulo: Atlas, 2009.

MINTZBERG, Henry. Ascensão e queda do planejamento estratégico. Porto Alegre: Bookman, 2004.

MOURA, Luciano Raizer. Qualidade simplesmente total. Uma abordagem simples e prática da gestão de qualidade. Rio de Janeiro: Qualitymark, 1997.

MOURA, Luiz Rodrigo Cunha; MOURA, L. E. L.; OLIVEIRA, C. T.; CUNHA, N. R. S. A percepção da qualidade em serviços: um estudo de caso do Banco Real de Itabira-MG. I Congresso de Administração, Unifenas, 2002

OLIVEIRA, Djalma de Pinho Rebouças de. Planejamento estratégico: conceitos, metodologia e práticas. São Paulo: Atlas, 2015.

ORLICKAS, Elizen da. Modelos de gestão: das teorias da administração à gestão estratégica. São Paulo: IBPEX, 2010.

PEREIRA, Marcos Aurélio. Metodologia cientifica. São Pulo: Atlas, 2002.

RASMUSSEN, U. W. Manual da metodologia do planejamento estratégico. São Paulo: Aduaneiras, 1990

REICHHELD, F. The Loyalty Effect, Harvard Business School Press. (1996). 
SANTOS, Leonardo Lemos da Silveira; ALVES, Ricardo César; ALMEIDA, Kenneth Nunes Tavares de. Formação de estratégias nas micro e pequenas empresas: um estudo no CentroOeste mineiro. Revista de Administração de Empresas, v.47, n.4, p.59-73, il. color, 2008.

SANTOS, T. O. D. Fidelização do cliente visando lucro e conquista de espaço no mercado. Monografia (Pós-graduação em Marketing). Faculdade Integrada AVM, Universidade Candido Mendes, Rio de janeiro, 2008. 42f. Disponível em : http://www.avm.edu.br/docpdf/monografias_publicadas/R200502.pdf . Acesso em: 30.04 .2018

SEBRAE. A fidelização de clientes como diferencial para a pequena empresa. Disponível em: <http://www.sebrae.com.br/sites/PortalSebrae/Fidelizaçãodeclientes> acesso em: 16.09.2018 as 09:24.

SELLTIZ, C.; WRIGHTSMAN, L. S.; COOK, S. W. Métodos de pesquisa das relações sociais. São Paulo: Herder, 2013.

SCHIFFMAN, L. \& KANUK, L. Comportamento do consumidor. LTC editora. 6 a ed. 2015.

VERGARA, Sylvia C. Projetos e relatórios de pesquisa em administração. 3.ed. Rio de Janeiro: Atlas, 2000.

WARD, T.; DAGGER, T. The complexity of Relationship Marketing for Service Customers. Brisbane: Journal of Services Marketing, 2007.

WHITELEY, Richard C.. A Empresa totalmente voltada para o cliente: do planejamento a ação; Tradução Ivo Korytowski - Rio de Janeiro: Campus, 1999.

Como citar este artigo (Formato ABNT):

PEREIRA, Laleska Zuza; LEITE, Márcia Maria. Fidelização de Clientes como Ferramenta Estratégica: Uma Pesquisa de Campo realizada com Clientes de Mercantis localizados na cidade de Brejo Santo-CE. Id on Line Rev.Mult. Psic., 2018, vol.12, n.42, p. 797-819. ISSN: 1981-1179.

Recebido: 19/10/2018;

Aceito: $23 / 10 / 2018$ 